\title{
DO ENSINO DE CONTEÚDOS AOS SABERES DO PROFESSOR: MUDANÇA DE IDIOMA PEDAGÓGICO?
}

\author{
IsABEL AuCE LeLIS*
}

\begin{abstract}
RESUMO: Este trabalho tem o objetivo de decifrar algumas das tendências da produção intelectual sobre formação de professores nos últimos vinte anos no Brasil, chamando a atenção para os "idiomas pedagógicos" que tiveram impacto entre os educadores. No mapeamento da literatura especializada, alguns autores/textos foram tomados como exemplares por representarem lógicas de pensamento marcantes a respeito do papel da teoria e da prática na formação docente. Do balanço efetuado, o que se verificou foi a ruptura de um idioma pedagógico, passando-se de uma pedagogia marcadamente conteudista sob a hegemonia de uma razão teórica para uma perspectiva que aponta para uma epistemologia da prática.
\end{abstract}

Palavras-chave: formação docente, idioma pedagógico, ensino de conteúdos, saber do professor, relação teoria/prática.

Assistimos na última década ao aparecimento de uma literatura internacional bastante fértil no campo da formação de professores, em especial sobre os conhecimentos incorporados e atualizados pelos professores em seus processos de vida, de trabalho e de formação.

Sob matrizes diversas, o que parece ser consenso é a valorização da prática cotidiana como lugar de construção de saberes. Em que pese a fertilidade da produção acadêmica há, contudo, zonas de sombra que precisam ser desvendadas, se considerarmos os desafios de uma escola de massa e o lugar que nela desempenha o trabalho do professor, especialmente em sociedades como a nossa que não equacionaram o problema da desigualdade social e escolar.

\footnotetext{
* Professora e pesquisadora do Programa de Pós-Graduação em Educação Brasileira e diretora do Departamento de Educação da PUC-Rio. E-mail: isabell @edu.puc-rio.br
} 
Se é verdade que a problemática específica do saber escolar e do saber docente, enquanto tal, só muito recentemente passou a se constituir em objeto de pesquisa no Brasil, também é verdade que veIhos temas já trabalhados desde a década de 1980 reapareceram travestidos com nova roupagem, sugerindo um retorno a questões que não foram ainda equacionadas pelas políticas e práticas de formação de professores como, por exemplo, os conhecimentos de que devem ser portadores os professores e que se atualizam na ação pedagógica.

Uma hipótese é a de que esse retorno não parece significar mera reprodução de perspectivas de análise já formuladas em outros contextos, mas redimensionamento de questões que estão no centro da problemática do trabalho docente como, por exemplo, o papel da teoria e da prática nos processos de formação de professores, os modos como os professores se relacionam com os saberes.

Neste movimento, o que parece estar em questão é o processo de produção de discursos com impacto no campo intelectual e que "exprimem maneiras diversas de definir quais são os 'problemas' e consequentemente o leque de soluções disponíveis para combatê-los" (Almeida e Perosa, 1999, p.1).

Dentro dos limites do texto, é nossa intenção analisar algumas das tendências do debate sobre formação de professores nessas últimas duas décadas no Brasil, buscando entender as lógicas de pensamento que fundamentaram e ainda fundamentam algumas propostas presentes na literatura educacional. Trabalhamos na perspectiva de que, sob determinadas condições de produção, foram elaborados "idiomas pedagógicos" sobre a formação e trabalho docente na perspectiva de responder aos desafios postos aos sistemas públicos de ensino. Trata-se de uma tentativa de reconstruir, de certa forma, uma trajetória intelectual nas continuidades e rupturas que apresenta.

\section{Em uma pedagogia dos conteúdos, qual a relação do professor com o saber?}

Em contrapartida à segunda metade dos anos de 1970, marcada pela crítica ao papel da escola na reprodução da estrutura de classes, florescem trabalhos voltados para o conhecimento dos fatores intra-escolares, como mecanismos de exclusão dos setores populares, considerando-se a "rede de expectativas e contradições que permeiam a prática pedagógica" (Souza, 2000, p. 43). 
Sob diferentes ângulos, é analisada a situação do magistério na tentativa de encontrar explicações para as precárias condições de funcionamento dos sistemas públicos de ensino, expressas em altas taxas de exclusão escolar, principalmente entre segmentos das camadas populares.

Em um texto que se tornou referência no campo dos educadores, Mello (1982) parte do caráter mediador da escola ${ }^{1}$ para estudar as representações e expectativas do professor face à escola, ao aluno e aos papéis que desempenha.

Trabalhando sobre o conceito de "representação" de Moscovici, ${ }^{2}$ bastante utilizado na investigação educacional, a autora busca dar conta tanto da forma singular como um corpo de idéias se processa no indivíduo, respeitando a sua contextura psicológica autônoma, como das condições sociais reais de sua produção (Lelis e Nunes, 1999).

A tese central de Mello passa, nesse momento, pela defesa da competência técnica do professor vista como mediação através da qual se realizaria o sentido político da educação escolar. Nestes termos, a competência técnica envolveria tanto o domínio dos conteúdos de ensino pelo professor como o seu entendimento a respeito das relações entre os vários aspectos da escola, incluindo-se o peso da formação sobre o modo como percebe a organização da escola e os resultados de sua ação.

Bem diversa da tendência tecnicista dos anos de $1970,{ }^{3}$ Mello denuncia ainda a lógica subjacente à organização do trabalho no interior da escola que acabara por fazer com que o professor perdesse seus instrumentos de trabalho: do conteúdo (saber) ao método (saber fazer), restando uma técnica sem competência. Na busca por mapear as causas da precariedade da prática docente, estaria a dificuldade do professor em se perceber como parte do problema do ponto de vista das deficiências de sua formação (Mello, 1982).

De certa forma, essa tese provoca impacto e gera um debate intelectual, na medida em que faz emergir uma polêmica em torno do significado de uma suposta concepção universal sobre competência, acima dos interesses de classe.

Independente das críticas recebidas, ${ }^{4}$ o texto de Mello torna-se paradigmático e representa uma forma de pensar o trabalho docente no que ele era mas também no que deveria ser, surgindo com força a noção de que a escola e, nela, o professor teriam um papel chave na transmissão do saber elaborado, sistematizado, erudito de forma a 
garantir à população a possibilidade de expressar de maneira elaborada os conteúdos da cultura popular que correspondem a seus interesses (Saviani, 1985).

Trabalhando nas diferenças entre o cientista e o professor do ponto de vista da relação com o saber, Saviani ${ }^{5}$ ajuda-nos a entender a constituição de um idioma pedagógico, onde o professor seria transmissor do saber e não produtor:

Enquanto o cientista está interessado em fazer avançar a sua área de conhecimento, em fazer progredir a ciência, o professor está mais interessado em fazer progredir o aluno. O professor vê o conhecimento como um meio para o crescimento do aluno; enquanto para o cientista o conhecimento é um fim, trata-se de descobrir novos conhecimentos na sua área de atuação. (Saviani, 1985, p.19)

Nessa perspectiva, o conhecimento viria de "fora para dentro", tendo uma dimensão instrumentalizadora do ponto de vista político social. Ao professor, caberia a organização dos processos, de métodos, de modo a garantir a apropriação pelos alunos.

(...) um professor de história ou de matemática; de ciências ou estudos sociais, de comunicação e expressão ou literatura brasileira etc., tem cada um, uma contribuição específica a dar em vista da democratização da sociedade brasileira, do atendimento aos interesses das camadas populares, da transformação estrutural da sociedade. Tal contribuição se consubstancia na instrumentalização, isto é, nas ferramentas de caráter histórico, matemático, científico, literário, etc. que o professor seja capaz de colocar de posse de alunos. (Saviani, 1982, p. 83)

No horizonte de pensar a formação do educador, Saviani afirmava a necessidade de que o curso de Pedagogia fornecesse uma fundamentação teórica que permitisse uma ação coerente, o desenvolvimento de uma consciência aguda da realidade em que os futuros professores iriam atuar e uma instrumentalização técnica que permitisse uma ação futura eficaz (Saviani, 1980, p. 60).

Como forma de garantir o cumprimento dessas finalidades, cada disciplina do curso de Pedagogia deveria ser trabalhada de modo que os alunos chegassem a uma teoria geral de educação "no nível atitudinal ('o que o educador precisa viver'), no nível crítico-contextual ('o 
que o educador precisa fazer'), no nível cognitivo ('o que o educador precisa saber'), no nível instrumental ('o que o educador precisa fazer')" (Saviani, 1980, p. 61).

Sua proposta conferia ao conhecimento científico e à reflexão filosófica uma centralidade enquanto instrumentos-chave, capazes de transformar positivamente os atributos negativos do senso comum ${ }^{6}$ em elementos característicos de uma consciência crítica (Bonamino, 1989). Em uma filosofia da educação que se afirmava radical, rigorosa e de conjunto, Saviani encontrava o fermento para uma educação revolucionária.

Analisando o pensamento político pedagógico de Saviani, Bonamino chama a atenção para o caráter problemático do papel emancipador conferido ao saber elaborado, dada a natureza iluminista que poderia estar contida nessa formulação:

a escola não educa a consciência social apenas através dos conteúdos críticos devidamente seqüenciados e dosados que transmite. A consciência da criança não se desenvolve tão somente através de conceitos que ela assimila em seu contato com os detentores da cultura elaborada, mas as condições para o desenvolvimento desta consciência crítica são criadas pela participação da criança na experiência social coletiva, a qual se compõe, em parte, das experiências práticas que a escola propicia através de sua organização interna e do sentido que assumem suas relações internas. (Bonamino, 1989, p. 205-206)

Em que pese o investimento intelectual por pensar uma pedagogia crítico-social dos conteúdos ${ }^{7}$ e, nela, o papel do educador, ${ }^{8}$ o que deve ser registrada é a influência desta tese sobre o campo dos educadores, provocando "discursos sobre teoria", expressões de um "abstracionismo pedagógico", "na obsessiva preocupação em descrever a escola e explicar os problemas educacionais a partir de hipotéticas relações do processo educativo com outros processos socioeconômicos" (Azanha, 1992, p. 46), em um claro superdimensionamento da teoria em detrimento da empiria.

Do ponto de vista da prática de pesquisa, os anos de $1980 \mathrm{fi}$ caram a nos dever, em termos do conhecimento sobre as práticas pedagógicas efetivas que estavam acontecendo na sala de aula. Fiorentini et al. (1998) reforçam essa crítica ao afirmarem que 
as pesquisas sobre ensino e formação de professores passaram a priorizar o estudo de aspectos políticos e pedagógicos amplos. Os saberes escolares, os saberes docentes tácitos e implícitos e as crenças epistemológicas, como destaca Linhares (1996), seriam muito pouco valorizados e raramente problematizados ou investigados tanto pela pesquisa acadêmica educacional como pelos programas de formação de professores. (Fiorentini et al., 1998, p. 314)

Na busca por efetuar um balanço da pedagogia crítico-social dos conteúdos, Libâneo (1999), quinze anos depois, procura atualizar o "conteudismo", chamando a atenção para as interpretações equivocadas que esvaziavam a abordagem, na identificação mecânica entre "conteúdo" e "matéria":

conteúdos são os conhecimentos sistematizados, selecionados das bases das ciências e dos modos de ação acumulados pela experiência social da humanidade e organizados para serem ensinados na escola; são habilidades e hábitos, vinculados aos conhecimentos, incluindo métodos e procedimentos de aprendizagem e de estudo; são atitudes e convicções envolvendo modos de agir, de sentir e de enfrentar o mundo. ${ }^{9}$

Mesmo alargando-se o sentido do que entendemos por "pedagogia dos conteúdos", permanece o desafio de pensar nas relações que o professor estabelece com os saberes, considerando-se que na ação prática, saberes de diferentes ordens (entre os quais situam-se os conteúdos de ensino) são por ele mobilizados.

Considerando-se que uma pedagogia fundada em conteúdos tinha como justificativa a transformação política da escola e da sociedade e colocava como necessidade o recurso aos conhecimentos universais, ao que assistimos foi "o florescimento de um discurso de culpabilização do professor, dramaticamente similar ao discurso de culpabilização dos alunos que florescera nos anos 60 e 70" (Almeida e Perosa, 1999, p. 5). Para as autoras,

é neste quadro que a formação de professores torna-se um problema a ser resolvido fora dos espaços desvalorizados da formação regular. À maneira dos programas de educação compensatória da década de 70 , as práticas de formação dos professores serão também definidas como oportunidade para o professor "compensar" a má formação recebida nos cursos regulares. (Idem, p. 6) 


\section{Na crítica à formação de professores, o primado da lógica relacional}

No interior do debate sobre a formação de professores, vão sendo aprofundados os problemas crônicos enfrentados pelas instituições formadoras: falta de articulação entre teoria e prática educacional, entre formação geral e formação pedagógica, entre conteúdos e métodos.

Em texto escrito em 1983, Candau e Lelis trabalham a relação teoria e prática no sentido de identificar, nas práticas de formação de especialistas e professores, as concepções que estariam informando aquela relação. Denunciando a perspectiva positivista que caracterizaria a dicotomia entre teoria e prática, muito presente nos currículos dos cursos, as autoras buscam na filosofia da práxis formulada por Vazquez (1977) um recurso para pensar uma visão de unidade entre os dois pólos na perspectiva de uma teoria revigorada, porque formulada a partir das necessidades da realidade educacional:

A teoria em si não transforma o mundo. Pode contribuir para sua transformação, mas para isto tem que sair de si mesma, e, em primeiro lugar, tem que ser assimilada pelos que vão ocasionar, com seus atos reais, efetivos, tal transformação. Entre a teoria e a atividade prática transformadora se insere um trabalho de educação das consciências, de organização de meios materiais e planos concretos de ação: tudo isso como passagem indispensável para desenvolver ações reais e efetivas. Nesse sentido, uma teoria é prática na medida em que materializa, através de uma série de mediações, o que antes só existia idealmente, como conhecimento da realidade ou antecipação ideal de sua transformação. (Vazquez, 1977, p. 206)

Se essa via hoje parece ser problemática, dada a supervalorização da teoria em detrimento da atividade cotidiana prática, considerando-se a infinitude do real e dos processos de expansão e de revisão do conhecimento, postos pelo fim do leninismo e a derrocada da União Soviética entre outros acontecimentos, o tema da práxis (que não se confunde com prática utilitária) pode ainda ajudar a pensar as relações entre conhecimento científico, prática social e saber docente, apesar da distância de tempo e dos novos desafios para a formação de professores no Brasil, até porque hoje somos menos arrogantes quanto ao poder da teoria na explicação e transformação do real. 
Considerando que até a primeira metade da década de 1980, a literatura educacional produzida está bastante marcada pela influência do marxismo nas leituras efetuadas por Kosik, Gramsci, Vazquez, entre outros, assistimos na segunda metade dessa década ao esforço de pensar a formação de professores para além das categorias de classe social, trabalho manual e trabalho intelectual, infra-estrutura e superestrutura, até porque o pessimismo pedagógico não havia estimulado a elaboração de trabalhos que apontassem "formas de organização escolar e práticas de sala de aula que pudessem favorecer a aprendizagem dos alunos de origem social desfavorecida" (Mello, 1993, p. 116).

Alguns textos são expressões desse esforço por superar uma perspectiva conteudista stricto sensu como, por exemplo, a reflexão desenvolvida por Candau (1997) em torno aos novos rumos dos cursos de licenciatura. $^{10}$

Trabalhando sobre algumas experiências desenvolvidas em unidades responsáveis pelo ensino da física, da história/geografia e da língua portuguesa, integrantes de instituições de ensino superior e médio de prestígio no Rio de Janeiro, Candau (1997) chama a atenção para os obstáculos que as universidades brasileiras precisam enfrentar na função de preparar consistentemente os professores para os sistemas de ensino: separação entre atividades de ensino e pesquisa, predomínio da lógica disciplinar em detrimento de uma prática interdisciplinar, supervalorização do lugar ocupado pelas faculdades de Educação em detrimento das unidades responsáveis pelo conteúdo específico.

Pensando alternativas para os cursos de licenciatura, Candau defende o primado do conteúdo específico sobre o conteúdo pedagógico na formação do professor:

A competência básica de todo e qualquer professor é o domínio do conteúdo específico. Somente a partir deste ponto é possível construir a competência pedagógica. Esta afirmação não implica a existência de uma relação temporal de sucessão, e sim de uma articulação epistemológica.

É a partir do conteúdo específico, em íntima articulação com ele, que o tratamento pedagógico deve ser trabalhado. Enquanto as unidades específicas não assumirem como responsabilidade própria a formação de professores, muito pouco poderão fazer as unidades de educação. O que se propõe é uma nova concepção e uma reestruturação das relações de poder presentes nas licenciaturas. Do ponto de vista conceitual, parte-se do conteúdo específico para trabalhar a dimensão pedagógica em íntima relação com ele. Assume-se que a liderança deve ser da área específica 
com a colaboração íntima das unidades de educação. A responsabilidade deverá ser partilhada intimamente, mas o primado é da área de conteúdo específico. Somente a partir desta mudança de eixo, que suscitará certamente muitas resistências, será possível construir uma nova perspectiva para os cursos de licenciatura. (Candau, 1997, p. 46)

Essa tomada de posição é importante porque revela a importância de se investir no saber disciplinar, sem o qual não se efetiva a atividade de transmissão de conhecimento, mesmo considerando-se que $o$ que ensinar teria a primazia sobre o como ensinar.

Levando-se em conta que, até então, a formação de professores vinha sendo analisada no plano político-pedagógico em sentido mais genérico, a proposta é provocadora, nesse momento, por duas razões. Primeiro, por deslocar o "centro de gravidade" da formação de professores para as unidades específicas, obrigando-nos a pensar em uma outra lógica que articula saber disciplinar e saber pedagógico, sugerindo que a natureza da formação é multidisciplinar e, portanto, mais complexa do que se supunha nas análises anteriores. Significou pensar o saber do professor como sendo proveniente de duas fontes (Tardif, Lessard e Lahaye, 1991) - conhecimento do conteúdo e conhecimento pedagógico -, embora sem a clareza do significado e do conteúdo do que se estava nomeando como conteúdo pedagógico.

A segunda razão está na defesa da interdisciplinaridade ao enfatizar uma integração interna que, partindo do conteúdo específico em direção ao pedagógico, garantisse a articulação a partir de núcleos temáticos (Candau, 1997). Considerando que a formação de professores em cursos de licenciatura se constituiu historicamente em um esquema onde predominava uma total separação entre formação geral e formação pedagógica, a idéia de núcleos temáticos parece promissora pois pode vir a romper com os "guetos" institucionais, muito fortes na estrutura universitária até hoje. E, mais, ao introduzir a dimensão epistemológica como eixo instituinte da formação de professores na premissa de que "o domínio consistente de uma área específica supõe uma adequada compreensão da construção do seu objeto, dos diferentes enfoques metodológicos possíveis e suas respectivas bases epistemológicas, de sua lógica e sua linguagem” (idem, p. 46).

Mesmo se considerarmos que a afirmação do primado do conteúdo específico sobre o conteúdo pedagógico poderia estar representando a hierarquização entre os campos do conhecimento, derivando-se o pedagógico de uma ciência básica, o trabalho teve o mérito de chamar a atenção para as relações de poder existentes no interior da universi- 
dade entre os que pesquisam e os que ensinam, destacando a importância e a necessidade da investigação sobre o ensino no horizonte da superação de uma visão intuitiva ou meramente política sobre a transmissão/apropriação do conhecimento.

Partindo da idéia de que a universidade de pesquisa admitiu formar professores como "espécie de tarifa que ela paga para poder fazer ciência em paz" (Menezes, 1986, p. 120), pensar a formação prévia de professores pela via da pesquisa empírica, na ótica disciplinar, representou um avanço, se considerarmos as resistências e problemas com que nos defrontamos institucionalmente na universidade.

Considerando ainda que perspectivas de análise têm uma história, identifico nesse trabalho coordenado por Candau (1997), com os problemas que provoca - de natureza epistemológica, política, pedagógica - o fermento para pensar as políticas de formação de professores sem o "discurso sobre a teoria" tão freqüente entre os educadores.

No balanço efetuado, contudo, com algumas exceções, chegamos à década de 1990 sem avançarmos sobre o conhecimento dos processos de ensino, de formação, presos a uma concepção de competência que pouco avançou sobre quem são os professores, o que sabem, o que não sabem, como ensinam, como aprendem, que problemas enfrentam no cotidiano de sua prática profissional.

Talvez porque hoje sabemos que sabemos menos e essa consciência nos fez menos arrogantes, mas mais cuidadosos em definir, indicar um projeto para formação de professores, sem as fórmulas teóricas abrangentes que invadiram o campo da educação até bem pouco tempo.

\section{O significado da prática cotidiana na constituição dos saberes do professor}

Na perspectiva de que "a constituição de um grupo de incompetentes implica a constituição simultânea de um grupo de competentes" (Almeida, 1999, p. 6), assistimos, desde meados da década de 1980, à expansão de programas de formação continuada no pressuposto de que, através de conhecimentos provenientes da universidade, os docentes se equipariam de ferramentas teórico-metodológicas que Ihes permitiriam refletir e modificar suas práticas (Lelis e Nunes, 2000). 
Sob a forma de cursos de rápida duração, de oficinas, esses cursos representaram a cisão entre os conhecimentos universitários e os saberes dos professores pois, salvo exceções, partiam (e chegavam) a uma perspectiva fragmentada do conhecimento, ao estabelecerem uma fratura entre a teoria (que passou a discurso) e a prática (substituída pela técnica) (Kramer, 1995).

Herdeiros de uma pedagogia centrada na transmissão do saber elaborado, representaram um modelo "clássico" de formação, fundado na hegemonia teórica enquanto a explicação do real, sendo a teoria confundida com a verdade (Brandão, 1992), com o agravante de se fazer discurso sobre a teoria.

Entretanto, na contramão desta tendência, sofremos também o impacto de uma literatura internacional que nos chegou nos primeiros anos da década de 1990, trazendo novos aportes à formação de professores. Seja pela via da ênfase na relação entre dimensão pessoal, profissional e organizacional da profissão docente (Nóvoa, 1992), ${ }^{11}$ seja pela via de que o saber docente provém de várias fontes e de que a prática cotidiana faz brotar o "saber da experiência" (Tardif, Lessard e Lahaye, 1991), ${ }^{12}$ ou ainda do habitus profissional como "gramática geradora de práticas" (Perrenoud, 1993), ${ }^{13}$ a fecundidade dessas propostas está, de um lado, na forte crítica à razão instrumental e, de outro lado, na valorização da prática individual e coletiva como lugar de aprendizagem dos conhecimentos necessários à existência pessoal, social e profissional (Dominicé, 1990).

De certa forma, é o texto de Tardif, Lessard e Lahaye em 1991 que vem complexificar a lógica conteudista, ao afirmar que a relação dos docentes com o saber não se reduz à transmissão de conhecimentos já constituídos, sendo a prática, expressão de múltiplos saberes, incorporados em âmbitos, tempos, espaços de socialização diversos. Este texto contribuiu para a demarcação de um novo idioma pedagógico na consciência de que a prática profissional está marcada por uma trama de histórias, culturas que ultrapassam a dimensão pedagógica stricto sensu.

Ou seja, sob ângulos diversos, estes autores ajudaram a pensar a constituição dos saberes dos professores, em um pauta diversa de uma pedagogia centrada no saber elaborado, ao refletirem sobre os limites da formação prévia e, nela, dos conhecimentos acadêmicos na constituição do saber docente; ao afirmarem a centralidade da instituição escolar enquanto locus de formação do magistério; ao revela- 
rem a força da experiência escolar passada enquanto aluno no desenvolvimento da prática pedagógica; e, finalmente, ao assinalarem o caráter de improvisação a marcar o trabalho docente.

De certa forma, esta produção efetuou a "curvatura da vara", ao conferir à prática uma instância de produção do saber profissional, de outra latitude se comparado ao papel do conhecimento que provém da universidade.

Ao problematizarem uma perspectiva centrada no saber acadêmico, estimulam o redimensionamento do sentido da teoria, tomando-a muito mais como hipótese, sendo a verdade considerada como processo, provisória e parcial (Brandão, 1992).

Considerando que ainda não temos uma tradição em pesquisa acumulada sobre os saberes do professor, sobre a experiência cotidiana como lugar de construção de saberes, e que vivemos em um momento de clara hegemonia do projeto neoliberal no campo da educação, algumas questões colocam-se como desafiadoras: Que cuidados precisamos tomar para não privilegiarmos em excesso a realidade intra-escolar, micro-social, e perdermos com isto dimensões contextuais do trabalho docente no plano político social mais amplo? Como evitar o superdimensionamento do pedagógico, indiferente às diferenças sociais de gênero, classe social e etnia, tão fortes em nosso país? Como lidar com a dimensão cognitiva articulando-a à esfera das culturas com seus ritos, símbolos e mitos?

Ou seja, trabalhar com a prática, social e profissional, como espaço de constituição dos saberes do professor, implica não perder de vista o universo cultural dos diferentes agentes sociais que fazem histórica e culturalmente a escola.

Mas há ainda outras questões trazidas por este idioma pedagógico. Que cuidados precisamos tomar para não resvalarmos para um praticismo em migalhas, na relativização quanto ao lugar ocupado pela teoria? Sob que critérios operaremos com a prática profissional, de modo a torná-la um espaço de construção de saberes rigorosos sem serem rígidos? Como o saber do mundo da experiência sensível pode ser transposto para uma razão que se quer dialógica e processual?

Se estas questões podem contribuir como bússolas em nossas pesquisas, certamente será a experiência prática e concreta, com a ajuda das lições do passado, que nos ajudará a buscar novos objetos, novos problemas, novos idiomas pedagógicos.

Recebido para publicação em 16 de janeiro de 2001. 


\section{Notas}

1. A autora utiliza a categoria da mediação para se referir a "processos de fatos existentes na realidade objetiva, que são ações recíprocas, a trama das relações que ocorrem entre partes, forças, fenômenos de uma totalidade" (p. 24).

2. Para Mello (1982), Moscovici deixa claro que as representações não constituem apenas o reflexo, invertido ou não da realidade de um objeto social, sendo diferentes das imagens, tal como estas últimas são entendidas em psicologia social. O que dá especificidade às representações "é que em cada ator singular elas se constituem pela mediação de sua subjetividade, a qual configura um modo próprio de se apropriar, reelaborar e praticar idéias" (p. 40).

3. Para Lelis, no tecnicismo, a preocupação estava voltada para a mera instrumentalização técnica, estando a formação de professores orientada pelo domínio de comportamentos e habilidades observáveis e mensuráveis ( p. 44).

4. A polêmica instalada expressou-se em dois textos publicados em Educação \& Sociedade, números 14 e 15, provocados pela tese de Mello (1982): um primeiro, de Nosella (1983), problematizando a competência técnica como momento prévio do compromisso político, e um segundo, de Saviani (1983), comentando o texto de Mello (1981) e respondendo a Nosella na perspectiva de mediar um conflito em torno à função política da escola e sua mediação pela via da competência técnica.

5. Para Gadotti, a pedagogia dos conteúdos foi desenvolvida no Brasil por Dermeval Saviani, Guiomar Namo de Mello, José Carlos Libâneo e Carlos Roberto Cury, apoiados por autores como Georges Snyders, Makarenko, Bernard Charlot, Bogdan Suchodolski e Mario Manacorda; situa-se como uma das vertentes da pedagogia progressista (p. 92).

6. Para Saviani (1980), "passar do senso comum à consciência filosófica significa passar de uma concepção fragmentária, incoerente, desarticulada, implícita, degradada, mecânica, passiva, simplista a uma concepção unitária, coerente, articulada, explícita, original, intencional, ativa e cultivada" (p. 5).

7. A Pedagogia Crítico Social dos Conteúdos é um movimento que nasce da reunião de intelectuais em torno da Ande. Para Libâneo, um dos seus principais ideólogos, o nome PSCS tem sua inspiração na leitura de $A$ mistificação pedagógica, de Bernard Charlot, obra com forte penetração entre os educadores.

8. O tema da formação do educador mobilizou o campo intelectual, expressando-se sobre a forma de publicações, encontros, seminários do norte ao sul do país, desde o início dos anos de 1980. Representava a oposição tanto ao especialista em conteúdo como ao técnico em educação (Pereira, 2000).

9. Entrevista de Libâneo, concedida por e-mail a alunos do programa de PósGraduação em Educação Brasileira, em maio de 1999. 
10. A pesquisa Novos Rumos da Licenciatura foi desenvolvida no período de 1985-1987 e contou com equipe constituída pelas professoras do Departamento de Educação da PUC-Rio Vera Maria Ferrão Candau (coord.), Menga Lüdke, Ana Waleska P. C. de Mendonça, Rosina Wagner e Yara Wall e alunos da pós-graduação.

11. Antonio Nóvoa foi um dos propulsores da tendência ao uso de histórias de vida na pesquisa sobre formação de professores, especialmente a partir da chegada, em 1992, da obra Vidas de professores, por ele coordenada.

12. Este artigo foi traduzido por Léa Paixão e publicado em 1991 na revista Teoria e Educação no 4. Deve ser considerado um trabalho inaugural no campo do saber docente no Brasil, expressão de um programa de pesquisa que reúne pesquisadores de várias universidades canadenses, como Maurice Tardif, Clermont Gauthier, Claude Lessard, Danielle Raymond, entre outros.

13. Nosso primeiro contato com o pensamento de Philippe Perrenoud deu-se através do livro Práticas pedagógicas, profissão docente e formação: Perspectivas sociológicas, publicado pela Dom Quixote, em 1993.

\title{
FROM TEACHING THE CONTAINS TO TEACHER'S KNOWLEDGE: A CHANGE OF THE PEDAGOGIC IDIOM?
}

\begin{abstract}
This work has the objective of to decipher a few tendencies of the intellectual production about teacher's education in the last years in Brazil, bringing the attention to the "pedagogic idioms" which caused impact among educators. In "mapping" specialized literature, a few authors/texts were taken as examples for they represented the logic of thought, markly about the significance of the theory and practice in the teacher's education. From the balance made, what was noticed, was a rupture from a pedagogy markly with contains to an epistemology of practice.
\end{abstract}

key words: teacher's education, pedagogic idiom, teaching contains, teacher's knowledge, relation theory-practice.

\section{Referências bibliográficas}

ALMEIDA, A. e PEROSA, G.S. Exclusão escolar e formação do magistério: Notas de pesquisa sobre uma relação não necessária. In: Anais da XXII Reunião anual da Anped, Caxambu, out. 1999, p. 1-14 (CD-Rom).

AZANHA, J.M.P. Uma idéia de pesquisa educacional. São Paulo: Edusp, 1992.

BONAMINO, A.M.C. O Pensamento pedagógico-político de Dermeval Saviani. Até que ponto Gramsci? Dissertação de mestrado em Educação, Departamento de Educação da PUC-Rio, 1989. 211p. 
BRANDÃO, Z.A. Teoria como hipótese. Teoria \& Educação nํ5, Porto Alegre: Pannônica, 1992, p.161-169.

CANDAU, V.M.F. e LELIS, I.A. A relação teoria-prática na formação do educador. In: CANDAU, V.M. F. (org.) Rumo a uma nova didática. 9a ed. Petrópolis: Vozes, 1999, p. 56-72.

CANDAU,V.M.F. Universidade e formação de professores: Que rumos tomar? In: CANDAU, V.M.F. (org.) Magistério, construção cotidiana. Petrópolis: Vozes, 1997.

DOMINICÉ P. O que a vida lhes ensinou. In: NÓVOA, A. e FINGER, M. (orgs.). O método (auto)biográfico e a formação. Lisboa: Pentaedro, Publicidade e Artes Gráficas Ltda, 1990.

FIORENTINI, D. e SOUZA e MELO,G.F. Saberes docentes: Um desafio para acadêmicos e práticos. In: GERALDI, C. (org.) Cartografias do trabalho docente: Professor(a)-pesquisador(a). Campinas: Mercado das Letras, ALB,1998, p. 307-335.

GADOTTI, M. Pensamento pedagógico brasileiro. São Paulo: Ática. 160p.

LELIS, I.A. e NUNES, C.M.F. A construção social do trabalho docente: Do estudo das "representações" às "histórias de vida". In: III Congresso Luso-Brasileiro de História da Educação. Escolas Culturas e Identidades. Livro de resumos. Coimbra, Fevereiro de 2000.

LELIS, I A. A Formação da professora: Da denúncia ao anúncio. $4^{a}$ ed. São Paulo: Cortez, 1989. 134 p.

LIBÂNEO, J.C. Democratização da escola pública: A pedagogia críticosocial dos conteúdos. São Paulo: Loyola, 1985, p. 45-56.

MELLO,G.N. Cidadania e competitividade: Desafios educacionais do terceiro milênio. São Paulo: Cortez, 1993. 194p.

. Magistério de $1^{\circ}$ grau. Da competência técnica ao compromisso político. São Paulo: Cortez, 1982. 151p.

MENEZES, L.C. de. Formar professores: Tarefa da universidade. In: CATANI, D.B. et al. (orgs.). Universidade, escola e formação de professores. São Paulo: Brasiliense, 1986, p.115-125.

NOSELLA, P. Compromisso político como horizonte da competência técnica. Educação \& Sociedade no 14, São Paulo: Cortez/Cedes, 1983, p. 91-97.

NÓVOA A. Os professores e as histórias de sua vida In: . (org.). Vidas de professores. Porto: Porto Editora, 1995. 214p. 
PEREIRA, J.E.D. Formação de professores: Pesquisas, representações e poder. Belo Horizonte: Autêntica, 2000. 167p.

PERRENOUD, P. Práticas pedagógicas, profissão docente e formação: Perspectivas sociológicas. Lisboa: Publicações Dom Quixote, 1993. 206 p.

SAVIANI, D.A. Pedagogia histórico-crítica no quadro das tendências da Educação Brasileira. ANDE - Revista da Associação Nacional de Educação №11, São Paulo: Cortez, 1985, p.15-23.

. Competência política e compromisso técnico ou o pomo da discórdia e o fruto proibido. Educação \& Sociedade no 15 , São Paulo: Cortez/Cedes, 1983.

. Escola e Democracia: para além da teoria da vara. ANDE - Revista da Associação Nacional de Educação, ano I, no 3, São Paulo: Cortez, 1982, p. 56-64.

. Educação senso comum à consciência filosófica. São Paulo: Cortez, 1980. 224p.

SOUZA, M.G. de S. Educação e diversidade cultural: Uma análise da proposta plural do município de Belo Horizonte, MG. Dissertação de mestrado em Educação, Departamento de Educação da PUC-Rio, Rio de Janeiro, 2000. 174 p.

TARDIF, M.; LESSARD, C. e LAHAYE, L. Os professores face ao saber: Esboço de uma problemática do saber docente. In: "Dossiê: Interpretando o trabalho docente". Teoria \& Educação no 4, Porto Alegre: Pannônica, 1991, p. 215-233.

VAZQUEZ, A.D. Filosofia da praxis. Rio de Janeiro: Paz e Terra, 1977. 454p. 